Portland State University

PDXScholar

5-13-1976

\title{
The Effect of Natural Childbirth Classes on Anxiety in Pregnant Women
}

Kitty M. Wilkinson

Portland State University

Follow this and additional works at: https://pdxscholar.library.pdx.edu/open_access_etds

Part of the Health Psychology Commons

Let us know how access to this document benefits you.

\section{Recommended Citation}

Wilkinson, Kitty M., "The Effect of Natural Childbirth Classes on Anxiety in Pregnant Women" (1976). Dissertations and Theses. Paper 2593.

https://doi.org/10.15760/etd.2590

This Thesis is brought to you for free and open access. It has been accepted for inclusion in Dissertations and Theses by an authorized administrator of PDXScholar. Please contact us if we can make this document more accessible: pdxscholar@pdx.edu. 
AN ABSTRACT OF THE THESIS OF Kitty M. Wilkinson for the Master of Science in Psychology presented May 13, 1976.

Title: The Effect of Natural Childbirth Classes on Anxiety in Pregnant Women.

APPROVED BY MEMBERS OF THE THESIS COMMITTEE:
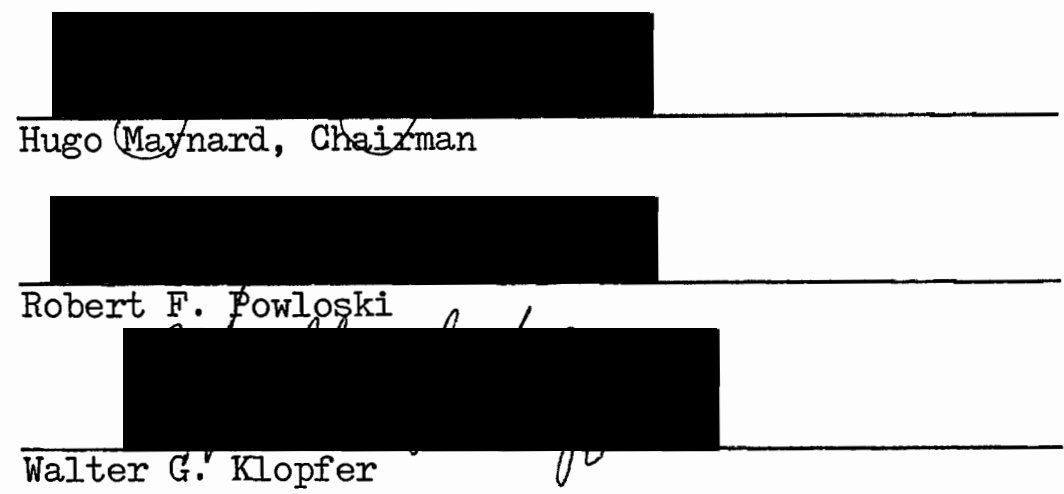

A study was conducted to investigate the claim made by proponents of the natural childbirth method that attendance in the program results in a decrease of the anxiety commonly associated with pregnancy and delivery. Seventy-two pregnant women filled out the A-State and A-Trait forms of the STAI twice in their obstetricians' offices at points which approximated $6 \frac{1}{2}$ and $8 \frac{1}{2}$ months along in their pregnancies. Subjects who elected not to attend natural childbirth classes evidenced significantly higher state and trait scores as compared to those scores of subjects who did attend classes. Implications for dealing with these differences are discussed in terms of the natural childbirth program. 
THE EFFECT OF NATURAI CHIIDBIRTH

CLASSES ON ANXIETY IN PREGNANT WOMEN

\author{
by
}

Kitty M. Wilkinson

A thesis submitted in partial fulfillment of the
requirements for the degree of

MASTER OF SCIENCE

in

PSYCHOLOGY

Portland State University

1976 
TO THE OFFICE OF GRADUATE STUDIES AND RESEARCH:

The members of the Committee approve the thesis of

Kitty M. Wilkinson presented May 13, 1976.
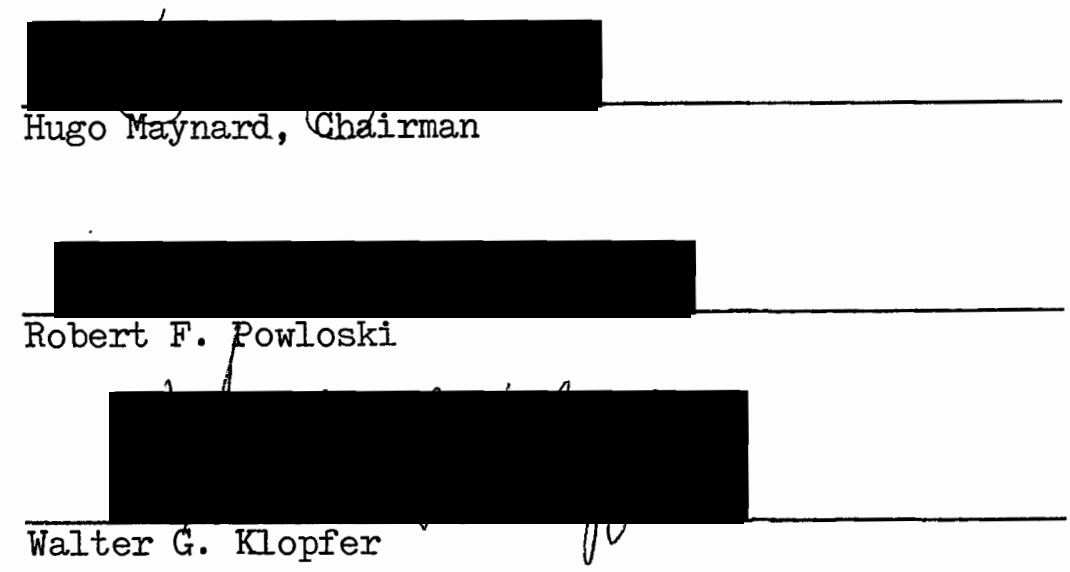

APPROVED:

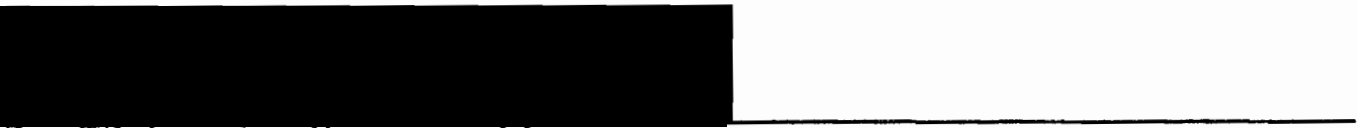

Robert E. Jones, Jr., Head, Department of Psychology

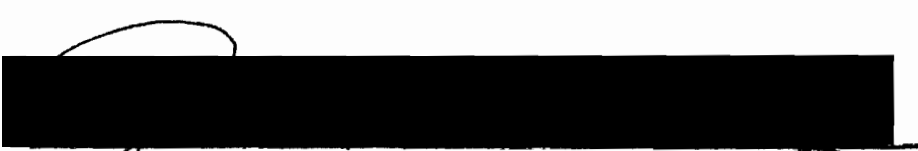

Richârd B. Halley, Acting Dean of Gqfoduate Studies and Research

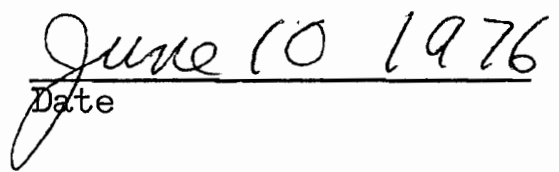


TABLE OF CONTENTS

PAGE

CHAPTER

I INTRODUCTION . . . . . . . . . . . . . . I

II METHOD . . . . . . . . . . . . . 9 9

Subjects . . . . . . . . . . . . . 9

Standardized Instrument . . . . . . . 10

Procedure . . . . . . . . . . . . . 13

III RHSULTS . . . . . . . . . . . . . . 15

First Test Administration . . . . . . . 20

Predictability Between Variables . . . . . 25

Second Test Administration . . . . . . . 31

IV DISGUSSION . . . . . . . . . . . . . . 35

Summary . . . . . . . . . . . . 35

Conclusions . . . . . . . . . . . 36

Recommendations ............ 41

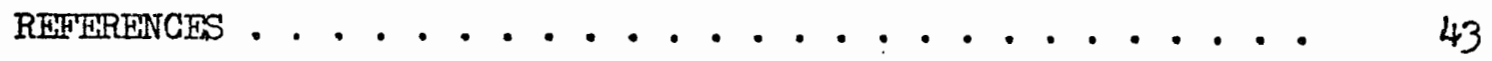

APPENDIX A. . . . . . . . . . . . . . . . . 46

Letter to Potential Participants . . . . . . 47

Face Sheet Number One . . . . . . . 48

Face Sheet Number Two . . . . . . . . 50

Self-Bvaluation Questionnaire . . . . . 51

APPENDIX B . . . . . . . . . . . . . . . . . . 52

Key to Correlation Matrix . . . . . . . 53

Correlation Matrix for Variables one Through

Seven................ 54 
iv

APPENDIX B

PAGE

Correlation Matrix for Variables Eight Through Fourteen . . . . . . . . 55

Correlation Matrix for Variables Fifteen Through Twenty-One... . . . . . . 56

Correlation Matrix for Variables Twenty-Two Through Twenty-Eight . . . . . . . . 57 


\section{INTKODUCTION}

Despite differences in various studies of the psychological effects of pregnancy, there is general agreement that some relationship exists between psychological factors and the course of pregnancy, although there is little agreement about specific results. Regardless of their theoretical framework, virtually all those who have studied emotional reactions in pregnancy agree on one issue: that all women experience an increase in anxiety and tension during this time.

An accumulating body of evidence tends to demonstrate that maternal anxiety is associated with complications in pregnancy and childbirth, and that various kinds of maternal emotional reactions can influence the fetal environment, the fetus, and its subsequent behavior. Three recently published books (Ferreira, 1969; Joffee, 1969; Richardson \& Guttmacher, 1966) offer excellent literature reviews of studies that have been concemed with the problems of maternal stress and anxiety during pregnancy. Copans (1974) points out that the characteristics of most human studies dealing with prenatal maternal influences have generally raised problems when an attempt is made to interpret the results. It is felt that the importance of emotional factors in the course and outcome of pregnancy has been demonstrated, although clear relationships have yet. to be estabiished.

Several investigators have hypothesized that anxiety is the key factor in pregnancy, and have confirmed their hypothesis by means of hospital records, case histories, questionnaj.res, interviews, clinical observations, projective techniques, and standardized tests. The tests used to measure anxiety in pregnancy have included the Minnesota Multiphasic Personality Inventory (MMPI), published by Hathaway and McKinley 
in 1943, the Taylor (1953) Manifest Anxiety Scale (TMAS), the Zuckerman (1960) Affect Adjective Check List (AACL), the IPAT Anxiety Scale (Cattell \& Scheier, 1963), self-ratings, ideal self-ratings, matermal anxiety ratings, and anxiety ratings as expected from others. The most widely used scale in studies of this kind has been the TMAS; high scores have been correlated with abnormal deliveries, total labor time, mean birth weights, obstetric complications, amounts of analgesia required during childbirth, marital conflict and irritability with husband and children, greater dissatisfaction with the motherhood role in terms of hostility, control, and rejection of homemaking, more negative childrearing attitudes, and more rejection of pregnancy and fear of harming the baby (Davids, DeVault, \& Talmadge, 1961a, 1961b; Davids \& DeVault, 1962). One specific study found that children of highly anxious mothers had statistically significant lower development quotients in both menta: and motor areas (Davids, Holden, \& Gray, 1963).

At the present time, the only large scale attempt designed to reduce maternal anxiety is the natural childbirth program, which is now available in most of the major cities in the United States. In contrast to traditional obstetrics, these programs are focused on the psychological needs of the prospective mother. Buxton (1962), Chertoik (1959), and Tanzer (1967) present good reviews of the theory, history, and development of the natural childbirth programs. A brief description of the content of the natural childbirth program is as follows: a woman who desires to receive natural childbirth preparation usually registers for a course about ten weeks before her expected delivery date. The courses are offered by either hospitals or private organizations, and generally the woman and her husband attend classes together along with several 
other couples. Couples learn about labor and delivery, medication and anesthesia, anatomy and physiology, concentration and relaxation measures, breathing techniques, muscular exercises, hygiene, fetal development, postpartum maternal care, and finally, care of the newborm infant (Bean, 1972).

One of the natural childbirth program's major claims is that they are designed to bring about a reduction or elimination of the anxiety generally associated with pregnancy and childbirth (Dick-Read, 1953; Wright, 1971). However, very little has been written in the acadenic: literature concerning objective evaluations of the natural childbixth programs. The few medical evaluations that have been done seem to reach similar conclusions about certain specific results. Significant differences have been found in the following areas: degrees of relaxation, amounts of medication required during labor and delivery, blood loss, convalescent time, matermal postpartum behavior, and infant postnatal behavior (Davis \& Morrone, 1962; Laird \& Hogan, 1956; Mandy, 19,52; Thoms \& Karlovsky, 1954).

To date, only two enpirical studies have addressed themselves to the relationship between psychological factors involved in pregnancy and childbirth with respect to the variable of class attendance in the natural childbirth programs: In a study of painless childbirth, the TMAS was administered during the 4 th and 8th month of pregnancy to different subsamples of married primiparous women taken from a larger sample at a French general hospital (Chertok, 1959). Ore group had refused the natural childbirth classes, and the other group was being prepared for childbirth by means of the natural childbirth classes. The more anxious women were found to be in the preparation group; the less anxious refused 
preparation but had the poorest confinements. The prepared women had greater behavioral control during labor and evidenced better relationships with the hospital staff than the unprepared group. The women in the preparation group, who were perhaps more anxious to start with, indicated (according to the authors) by wanting preparation, that they were willing to accept reassurance or actually sought it. Reporting inadequacies prevent a satisfactory interpretation of the data in this particular study .

Another investigator studied private patients from an upper socioeconomic class and from high.educational backgrounds, using both primiparous and multiparous married women (Tanzer, 1967). There were 22 women in the natural childbirth group and 14 women in the control group. The TMAS was administered along with a battery of psychological tests during the 7 th month of pregnancy and repeated during the 9 th month. No initial difference was found between groups on any measure, including anxiety. The only effect of taking a natural childbirth class was found to be a positive change in attitude towards the pregnancy.

These results alone suggest that several different kinds and levels of anxiety are involved in the study of pregnant women. At present, it seems as if the notion of anxiety in pregnancy has been insufficiently analyzed and perhaps inadequately measured by the TMAS. A serious difficulty concerns the nature of anxiety during pregnancy and what the Taylor scale really i:easures -- in particular, whether it reflects the amounts of anxiety existing at the different stages of pregnancy, or the extent to which such anxiety is expressed. Doty (1967) found no relationship between anxiety and pregnancy using the TMAS and MMPI, and concluded that 
one may believe pregnancy to be influenced by psychological factors even though this influence cannot be demonstrated.

The Taylor scale was originally developed by a group of experimental psychologists interested in studying human subjects in various learning situations (Sarason, 1960). In view of the absence of measures of individual differences in anxiety, the scale was widely 'adopted by researchers who began studying the relationship between anxiety and a great variety of behaviors and situations (Jenkins \& Lykken, 1957). The TMAS is generally viewed as an instrument that measures relatively stable individual differences in anxiety proneness, and may be an inappropriate measure of the anxiety experienced by women because of the uniqueness of the pregnancy period.

One noticeable exception to the indices generally used to measure anxiety is the State-Trait Anxiety Inventory (STAI) used by Edwards (1969), who investigated emotional and attitudinal factors associated with pregnancy and obstetric complications. The STAI is comprised of separate self-report scales for measuring two distinct anxiety concepts: state anxiety (A-State) and trait anxiety (A-Trait). The STAI A-State scale was given at the same time each week to women during the seven week period prior to delivery. While no significant differences were found in scores between women who had normal or abnormal deliveries, the A-State scores of the normal group first decreased and remained at a relatively low level until a point near delivery, at which time they increased markedly. These results notably coincide with a study done by Grimm (1961), who found psychological tension to be at its greatest during the last half of the last trimester. Edwards found the level of A-State in the abnormal group to increase approximately four weeks prior to delivery 
and then to decrease markedly during the week prior to delivery.

The STAI was designed by Spielberger, Gorsuch, and Iushene (1968),

and has been used in more than 500 studies in the past five years. The STAI has just recently been selected for research purposes by obstetricians and neonatologists at George Washington University for a large scale normative study of anxiety in pregnant women, and also by a research group in the Department of Psychiatry at Oxford University for a study of changes in anxiety in pregnant women (C. Spielberger, 1974). The STAI provides separate assessments of how anxious a person is currently, and how anxious he is characteristically. A score on the A-State form indicates how a person feels now, and often reflects situational factors that may influence anxiety levels. A score on the A-Trait form represents a more sustained level of anxiety, and may be related to the individual's pronemess to experience anxiety under certain kinds of circumstances (Roche, 1974). Previous research has demonstrated that scores on the STAI A-State scale increase in response to various kinds of stress and decrease as a result of relaxation training (Spielberger, et al., 1970).

The concept of a distinction between state and trait anxiety was first introduced by Cattell and Scheiex (1961), and has received considerable attention in research relating to anxiety phenomena. The following contributors to two recent volumes entitled Anxiety: Current Trends in Theory and Research, edited by C. Spielberger (1972), have acknowledged and lent support to the significance of the state-trait distinction associated with anxiety reactions: Averill, Barrett, Beck, Cattell, Epstein, Izard, Lazarus, Levitt, Mandler, Martin, Myers, Phillips, Sarason, and Spielberger. For the purposes of the present study, the concepts of 
state and trait anxiety will be defined precisely in accordance with the

Trait-State Anxiety Theory, presented by Spielberger (I972):

State anxiety (A-State) may be conceptualized as a transitory emotional state or condition of the human organism that varies in intensity and fluctuates over time. This condition is characterized by subjective, consciously perceived feelings of tension and apprehension, and activation of the autonomic nervous system. Level of A-State should be high in circumstances that are perceived by an individual to be threatening, irrespective of the objective dariger; A-State intensity should be low in nonstressful situations, or in circumstances in which an existing danger is not perceived as threatening.

Trait anxiety (A-Trait) refers to relatively stable individual. differences in anxiety proneness, that is, to differences in the disposition to perceive a wide range of stimulus situations as dangerous or threatening, and in the tendency to respond to such threats with A-State reactions. A-Trait may also be regarded as reflecting individual differences in the frequency and the intensity with which A-States have been manifested in the past and in the probability that such states will be experienced in the future. Persons who are high in A-Trait tend to perceive a larger number of situations as dangerous or threatening than persons who are low in A-Trait, and to respond to threatening situations with A-State elevations of greater intensity. ${ }^{1}$

Several methodological issues arise in the measurement of anxiety states. McReynolds (1968) reviewed a total of 88 methods in his survey of suggested procedures for assessing anxiety. Spielberger (1972) mentions a critical analysis of the methodological factors that are encountered with the use of self-report measures presented by Wilde (1972). According to Spielberger, Wilde's general conclusion is that such scales may be regarded as verbal surrogates for behavior samples if the following assumptions are met: that people are motivated to report honestly, and that they are willing and able to correatly describe their feelings and behavior.

ICharles D. Spielverger, "Anxiety as an Emotional State," Anxiety: Current Trends in Theory and Research, ed. C.D. Spielberger (New York, 1972), p. 39 . 
It is clear that additional research in relation to more appropriate measurernent techniques is needed in order to determine the relationship between natural childbirth training and anxiety during the course of pregnancy. The STAI appears to provide a comprehensive assessment of anxiety. The basic rationale behind this instrument is that it is meaningful to distinguish between anxiety as a transitory state and as a relatively stable personality trait.

The outstanding conclusion that emerges from a survey of the literature on natural childbirth is that very little has been written on the subject. Attempts at any sort of an objective evaluation are alnost nonexistent, and the results are somewhat confusing. The evaluations that have been attempted have concentraied almost exclusively on the medical aspects of natural childbirth and not on the psychological aspects. The study of natural childbirth txaining programs is of direct interest to psychologists. Anxiety during pregnancy is considered to be pathogenic and attempts at its elimination have obvious importance. The purpose of the present investigation was to investigate the claim made by proponents of the natural childbirth method that attendance in the program results in a decrease of the anxiety commoniy associated with pregnancy and delivery, and to determine if there were essential differences between women who elect to attend natural childbirth classes and women who elect not to attend such classes. 
METHOD

Subjects: Seventy-two pregnant women comprised the subjects for the present investigation. All subjects were being seen in one of three obstetrical clinics in the Portland area. Due to the ethical issues involved in dealing with human factors research, assigning subjects randomIy to conditions was considered unfeasible. The subjects were divided into the following three groups at the time of the first testing administration: those who planned to attend natural childbirth classes during the present pregnancy, those who did not plan to attend, and those who were undecided. At the tine of the second testing administration, the subjects were placed into two groups: those who had atiended natural childbirth classes and those who had not. It was determined during the design of the study, that a sample size of 28 subjects per group was desirable.

Cooperation of the obstetricians had been solicited after the study had been approved by the Human Subjects Research Review Committee at Portland State University, and after the study had been outlined to the obstetricians in detail. Initial contact with the obstetricians was made by an interested physician in the Portland State University Health Service. Each obstetrician was able to supply subjects who fell into both categories: those who attended and those who did not attend natural childbirth classes during their pregnancies. All of the obstetricians enlisted the aid of their supporting staff members to contact and to administer the testing materials to the subjects. The staff members were instructed not to select particular subjects for the study. Any woman being seen in the clinics who was approximately six months pregnant was 
considered eligible to participate. The staff members have reported that $5 \% ?$ most of the women who were approached about the study were interested and $41 \%$. willing to cooperate as research subjects for the present investigation. Staff members handed out a written letter to all potential participants when they showed up at the clinics for routine obstetrical examinations. The letter stressed the general nature of the study and requested voluntary involvement on the part of the potential participant. The subjects were told that the study was about the psychological aspects of complian pregnancy, and that the research results might ultimately be of benefit altruismk to pregnant women in the future. The subjects were told that involvement consisted of filling out two short questionnaires, and that any questions peiceived as personal could be left blank. It was stressed that all information would be kept completely confidential, and that the investigator would never have access to the names of the subjects who participated in the study. All of the subjects were promised that a copy of the research results would be made available to them through their obstetricians' offices. The final statement in the letter was that the present study was an independent one, and the participants were asked not to request further information about it from their obstetrician or his staff members. A copy of this letter may be found in Appendix A.

Standardized Instxument. The A-State and A-Trait forms of the STAI were administered to all subjects. The STAI was developed to provide reliable, brief self-report measures of both state and trait anxiety. Since most anxiety scales measure trait anxiety, a large number of items embodying content of proven relationship to the most widely used A-Trait scales were rewritten so that each item could be administered with different instmations to measure state or trait anxiety. The essential 
qualities that are evaluated by the A-State scale involve feelings of tension, apprehension, worry, and nervousness. The A-State scale defines a continuum of increasing. levels of anxiety: low scores indicate states of calmness, intermediate scores indicate a moderate level of tension, high scores indicate intense apprehension. Evidence of content and concurrent validity, reliability, internal consistency, and construct validity may be found in the STAI test manual (Spielberger, 1968).

The STAI is a paper-and-pencil test, designed to be self-administering, with complete instructions printed on the test form for both scales. The title printed on the test form is "Self-Evaluation Questionnaire," with the scales printed on opposite sides of the test form. The teșt has no time limit, but completion of both forms seldom requires more than fifteen minutes. Both scales consist of 20 self-report items. The subject responds to each item by blackening the appropriate number to the right of the test form. The four categories for the A-State scale are: 1. not at all, 2. somewhat, 3. moderately so; 4. very much so. The categories for the A-Trait scale are: 1. almost never, 2. sometimes, 3. often, 4. almost always. A copy of these scales may be found in Appendix A.

Face Sheet \#1. A face sheet was attached to the STAI for the first test administration, requestiog information on a number of variables. These included age, marital status, educational and income level, the number of previous pregnancies as well as the number of children presently living at home, and whether or not this was a planned pregnancy. Information was also requested about general state of health, previous menstmal periods, weight gain, special health problems associated with the present pregnancy, and general attitude towards the present pregnancy. 
Subjects were asked if their mothers had told them what to expect in labor and delivery and if they had described their childbirth experiences to them, and they were asked to list their prime sources of information about childbirth.

Subjects were asked if they had ever taken a course in baby care, if they were interested in doing so, and if they planned to take such a course during the present pregnancy. They were also asked if they perceived their obstetricians as being supportive, and if they felt their obstetricians were satisfied with their progress. Subjects were asked how many weeks pregnant they. were at the time of the first testing administration, if they were interested in breastfeeding, and interested in seeing the baby being born. They were also asked if their husbands were interested in attending labor and delivery, if they had ever attended a natural childbirth course, and if they planned to attend one during this pregnancy. Subjects were asked to give reasons for their choice of attendance in such classes or choice of nonattendance. Those who responded that they planned to attend were asked what motivated their interest in the natural childbirth approach, and specifically what they planned to get out of the course. Finally, all subjects were asked to list their reasons for selecting their particular obstetrician.

Face Sheet \#2. A facs sheet was attached to the STAI for the second testing administration, requesting information on a number of variables. These included how many weeks the subject was pregnant, how things had been going in general, if there were any special emotional or physical problems at the time, how much weight had been gained to date, and if their obstetrician was satisfied with their progress. They were asked if they had attended a course in baby care during their pregnancy, 
and if so, the name of the course and where it was held. Subjects were also asked if they had attended a natural childbirth course, and if so, the name of the course and where it was held. For those subjects who did attend a natural childbirth course, they were asked what their reaction to the course was, as well as their husband's reaction, and they were asked how frequently they practiced the exercises that they had learned. Finally, all subjects were told to feel free to comment on any aspect of pregnancy that they felt was important and should be included in the present study. A copy of both Face Sheet \#1 and Face Sheet \#2 may be found in Appendix A.

Procedure. The materials for the testing administrations were coded in the following manner: Face Sheet I (IA), STAI (IB), Face Sheet II (IC), STAI (ID). Each subject had a different set of coding nunbers; for example: subjëct number two's codes were $2 \mathrm{~A}, 2 \mathrm{~B}, 2 \mathrm{C}, 2 \mathrm{D}$. All testing materials were kept in the obstetricians' offices completely separated from the subjects' medical histories, and stored in the offices until testing of all subjects was completed for each administration. A small slip of paper was attached to each set of testing forms with the subject's name and date of testing written on it, so that staff members could keep accurate records of each subject's code number. The name tags were removed from the testing materials before the investigator received the completed questionnaires, in order to ensure complete confidentiality .

All subjects took the testing sessions in either the waiting rooms or the examination rooms of the obstetricians' offices in order to provide relatively standardized testing conditions. At the time of the first test administration, all subjects filled out Face sheet \#IA and 
STAI \#IB. The subjects were approximately six and one-half months pregnant, and none had begun natural childbirth classes. At the time of the second test administration, which fell at an interval approximately two months later than the first, all subjects filled out Face Sheet \#IC and STAI \#ID. The subjects were approximately eight and one-half months pregnant, and those who had enrolled in natural childbirth classes were either nearing completion of the classes or had finished them. Staff members kept track of each subject's progress and handed out the questionnaires on dates which approximated the desired two month testing interval. As far as it could be determined, they provided little or no help in filling out the Face Sheets or STAI's so that the subjects were able to respond freely to all of the requested information. 
RESUITS

The sample consisted of 72 pregnant women who were being seen in one of three obstetrical clinics in the Portland area. Their ages ranged from 18 to 38, with the mean age being 25.5. Age was found to correlate significantly with income level, the number of times previously pregnant, the number of children presently living at home, and attendance at natural childbirth classes during a previous pregnancy. Age was found to be significantly negatively correlated with expressed interest in taking a course in baby care, and attendance at natural childbirth classes during the present pregnancy.

Ninety-nine percent of the sample were married and 75 percent stated that this was a planned pregnancy. Marital status correlated with planned pregnancies, perceived obstetrician support and satisfaction, and husband interest in attending labor and delivery. A negative correlation was found between marital status and state anxiety. Negative correlations were also found between planned pregnancies and the number of children presently living at home, desire to attend natural childbirth classes during this pregnancy, state anxiety, and trait anxiety. Positive correlations were found between planned pregnancies and marital status, educational level, and income level.

The educationai levels of subjects in the study ranged from completion of grade school through completion of graduate school, with the mean educational level being completion of one year of college. The income levels ranged from under $\$ 5,000$ per year through between $\$ 40,000$ and $\$ 45,000$ per year, with the mean income level falling between $\$ 10,000$ and $\$ 15,000$ per year. Educational level correlated positively with income 
level, planned pregnancies, perceived obstetrician support and satisfac.-. tion, husbands' interest in attending labor and delivery, and previous attendance at natural childbirth classes during a former pregnancy. Negative correlations were found between educational level and expressed interest in taking a course in baby care, state anxiety, and trait anxiety. Positive comrelations were found between income level and age, education, planned pregnancies, perceived obstetxician satisfaction with the subjects' progress, interest in seeing the baby being born, husband interest in attending labor and delivery, previous attendance at natural childbirth classes during a former pregnancy, and expressed interest in attending classes during this pregnancy.

- The number of previous pregnancies as well as the number of children presently living at home ranged from zero to four, with the means being 1.0 and $.74,{ }^{\circ}$ respectively. Negative correlations were found between the number of previous pregnancies and expressed interest in attending natural childbirth classes, and interest in taking a course in baby care during the present pregnancy. Positive correlations were found between the number of previous pregnancies and age, as well as the number of children presentiy living at home. The number of children presently living at home was found to be negatively correlated with planned pregnancies, interest in taking a course in baby care and attending natural childbirth classes, and also the number of weeks pregnant at the time of the first test administration. The number of months pregnant when the subjects began the study ranged from 5 to 7.5 , with the mean number of months being 6.28. The number of months pregnant at the time of the first test administration was found to be positively correlated with the 
subjects' perception of obstetrician satisfaction, husband interest in attending labor and delivery, and with expressed interest in attending natural childbirth classes.

Ninety percent of the sample rated their general health as good, while 12.5 percent stated that they had special health problems associated with the present pregrancy. The amount of weight gained during this pregnancy at the time of the first test administration ranged from under 10 pounds through between 30 and 35 pounds, with the average weight gain being 15 pounds. Weight gain correlated positively with the subjects' perception of obstetrician support. It was found to be negatively correlated with subjects' interest in seeing the baby being borm.

Ninety-four percent of the sample stated that their general attitude towards the present pregnancy was favorable, while six percent expressed negative 'feelings. General attitude correlated positively with general health, menstrual history, and interest in seeing the baby being born. General attitude was found to correlate negatively with state anxiety.

All of the subjects were asked to list their prime sources of information about pregnancy and delivery. The mean number of listed sources was computed to be 1.4 , with a range of zero to four sources. The most frequently listed responses included mother, doctor, books, and previous pregnancies. Nine percent stated that their mothers had given them adequate information about childbirth, 50 percent stated that their mothers had briefly discussed it, and 41 percent stated that their mothers had not discussed childbirth experiences with them at all. Out of the subsample of women whose mothers had given descriptions of their own experiences in labor and delivery, 10 percent reported that their 
mothers' experiences were good, 67 percent reported that they were fair, and 23 percent reported that they were poor. The subjects' mothers' description of childbirth experiences was found to be negatively correlated with the subjects' perception of obstetrician support.

Thirty-five percent of the sanple stated that they had taken a course in baby care in the past, and the same percentage expressed interest in taking a course in baby care during this pregnancy. Although 35 percent were interested, only 25 percent stated that they planned to enroll in such a course during the present pregnancy. Expressed interest in taking a course in baby care positively correlated with husbands' interest in attending labor and delivery, as well as interest in taking natural childbixth classes. Negative correlations were found between interest in a baby care course and age, number of children presently living at home, and special health problems associated with this pregnancy. Enrollment in a baby care course was found to be positively correlated with expressed interest in attending natural childbirth classes, and negatively correlated with age, educational level, number of previous pregnancies, and the number of children presently living at home.

Eighty-six percent of the sample stated that they felt their obstetricians were quite supportive, and the remaining 14 percent stated that their obstetricians were somewhat supportive. Perceived obstetrician support was found to be positively correlated with marital status, educational level, weight gain, previous attendance at a course in baby eare, husband interest in attending labor and delivery, and with perceived obstetrician satisfaction of the subject's progress. Perceived obstetrician support was found to be negatively correlated with special health problems associated with this pregnancy. Only one percent of the entire 
sample stated that their obstetricians were not satisfied with their progress; ninety percent stated that their obstetricians were quite satisfied, and nine percent did not know. Perceived obstetrician satisfaction was found to be positively correlated with marital status, educational level, the number of weeks pregnant at the time of the first test administration, and perceived obstetrician support. Obstetrician satisfaction was found to be negatively comelated with state anxiety.

Eighty-two percent of the sample stated that they were interested in breastfeeding. Breastfeeding was found to be positively correlated with the subject's mother keing the prime scurce of information a,bout childbirth. Eighty-three percent of the sample stated that they were interested in seeing the baby being born. Interest in this was positively correlated with income level, general attitude towards the pregnancy, husband interest in attending labor and delivery, and with expressed interest in attending natural childbirth classes. Negative correlations were found between interest in seeing the baby being born and weight gain, as well as with trait anxiety scores.

Twenty-three percent of the sample stated that their husbands were not interested in attending labor and delivery, seven percent stated that their husbands were unsure at this time, and 70 percent stated that their husbands were interested. Husband interest was found to be positively correlated with educational and income level, the number of weeks pregnant at the time of the first test administration, interest in taking a course in baby care, perceived obstetricians' support, interest in seeing the baby being borm, arid expressed interest in attending natural childbirth classes during the present pregnancy. Husband interest in attending labor and delivery was found to be negatively correlated with both 
state and trait anxiety test. scores.

Ninety-two percent of the sample stated that they had not taken natural childbirth classes before, and 38 percent of the sample stated that they planned to attend natural childbirth classes during this pregnancy. Eleven percent were undecided at the time of the first test administration. Attendance at natural childbirth classes duxing former pregnancies was found to be positively correlated with educational and income level, and also with age. Previous attendance was found to be negatively correlated with the subjects' mothers' descriptions of their childbirth experiences. Expressed interest in attending natural childbirth classes during this pregnancy was found to be positively correlated with income level, planned pregnancies, interest in taking a course in baby care, interest in seeing the baby being born, and husband interest in attending labor and delivery. Negative correlations were found between expressed interest in attending natural childbirth classes during this pregnancy and age, number of previous pregnancies, subjects' mothers' descriptions of childbirth experiences, previous attendance at a course in baby care, and trait anxiety test scores,

At the time of the first test administration, 26 subjects stated that they planned to attend natural childbirth classes during this pregnancy, 37 subjects stated that they would not attend, and nine subjects were undecided. State arxiety test scores in the subsample of subjects who planned to attend natural childbixth classes ranged from 22 to 52 , with a mean score of 32.23 and a standard deviation of 7.42 . State scores in the undecided group ranged from 20 to 45 , with a mean score of 32.0 and a standard deviation of 8.15. A Mann-Whitney U-Test yielded a $\underline{z}$ value of $.75(\mathrm{~N}=63)$, which is not significant at the five percent level, 
showing that the medians of the two groups are equal. No analysis was performed on the test scores of the subsample of subjects who were undecided as to whether they would attend natural childbirth classes at the time of the first test administration.

State anxiety test scores were found to correlate with trait anxiety test scores in a high, positive direction. Negative correlations were found between state scores and marital status, educational level, planned pregnancies, general state of health, general attitude towards the present pregnancy, and with perceived obstetrician satisfaction. At the time of the first test administration, trait anxiety test scores in the subsample of subjects who planned to attend natural childbirth classes during this pregnancy ranged from 24 to 58, with a mean score of 33.12 and a standard deviation of 7.03. Trait scores in the subsample of subjects who did not plan to attend ranged from 23 to 61, with a mean score of 38.76 and a standard deviation of 8.81 . Trait scores in the undecided group ranged from 21 to 49 , with a mean score of 35.22 and a standara deviation of 9.13. A Mann-Whitney U-Test yielded a $\underline{z}$ value of $2.69(\mathrm{~N}=63)$, which is significant at the one percent level, showing that the chance of the medians of the two groups being the same is very small. As previously mentioned, trait anxiety test scores were found to correlate with state scores, and were also found to be positively correlated with special. health problems associated with the present pregnancy. Negative correlations were found between trait anxiety test scores and educational level, planned pregnancies, general state of health, interest in seeing the baby being borm, husband interest in attending labor and delivery, and expressed interest in attending natural childbirth classes during the present pregnancy. 
Fearson Product Moment. Correlations were computed on all of the 28 variables taken from the first test administration. All of the aforementioned correlations were found to have a z value greater than plus or minus $1.96(\mathrm{~N}=72)$, yielding $\underline{\underline{x}}$ values which are statistically significant at least at the five percent Jevel, using a two-tailed test. A correlation matrix may be found in Appendix B.

All of the subjects were asked at the time of the first test administration to give their reasons for stating whether or not they planned to attend natural childbirth classes during the present pregnancy. Some of the subjects in the subsample of women who planned to attend gave more than one reason, which resulted in a 152 percent response rate to that particular question. Thirty-two percent of those who planned to attend stated that the classes had been highly recommended to them by friends. Thirty-three percent stated that they wanted their husbands to be involved with the delivery of their child. Sixty-one percent stated that since their husbands would be with them in labor and delivery, they felt it would be beneficial to both prospective parents to be knowledgeable about what to expect in the hospital. Nine percent stated that they planned to attend classes because of interest in the natural childbirth approach, and one percent stated that they were frankly curious about the course itself. Twelve percent stated that they hoped an easier labor and delivery would be the end result of participating in the classes, and four percent stated that due to a very difficult formex delivery, they were willing to try the natural childbirth approach.

Ninety-four percent of the women in the subsample of subjects who did not plan to attend classes responded to the above mentioned question. Twenty-one percent of these subjects cited lack of time as their reason 
for not attending classes, and sixteen percent cited transportation problems as their reason. Seventeen percent had attended clasises during former pregnancies, and did not plan to take a refresher course during this pregnancy. Fifteen percent stated that their husbands could not or would not attend labor and delivery. Seven percent stated that they planned to have a Cesarean Section, and fifteen percent stated firmly that they desired to receive drugs during childbirth. Two percent stated that their former labors and deliveries had been relatively painless, and one percent cited a medical background as the reason for not wishing to attend natural childbirth classes.

All of the subjects in the subsample of women who planned to attend classes were asked what reasons in particular motivated their interest in the natural chilabirth approach, which resulted in a 143 percent response rate. Nirieteen percent cited expectations of relief of pain in labor and delivery as their main reason, and 10 percent cited severe pain in past deliveries as the principle motivating factor. Fourty-two percent stated that they desired their husbands' help and support, and twenty percent stated that they felt the natural childbirth approach would be more meaningful and enjoyable than more traditional obstetrical methods. Thirty percent expected that the classes would alleviate the anxiety associated with labor and delivery, and $\geqq$ lso stated that they did not want to be afraid of the unexpected in the hospital. Nine percent stated that they wanted to be awake to see and feel the baby being borm, and another nine percent were against using drugs which may have unpleasant side effects for themselves, or a direct impact on the baby. Four percent stated that the resultant effect of the classes should be a less traumatic experience for themselves as well as the baby, 
All of the subjects in. the subsample of women who planned to attend natural childbirth classes were asked what they expected to get out of the course, which resulted in an $8 / 4$ percent response rate. Twenty-seven percent cited general information about childbirth, and eight percent cited specific birth techniques. Thirteen percent cited physical preparation, and six percent cited mental preparation for the forthcoming event. Eight percent were specifically interested in learning breathing exercises, four percent in gross muscular exercises, and three percent in relaxation techniques: Fourteen percent expected increased husband support as a result of attending the classes, and one percent stated that they expected the classes to relieve their anxiety.

All of the subjects in the entire sample were asked to list their reasons for selecting their particular obstetrician, which resulted in a 123 percent response rate. Thirty-nine percent stated that their obstetrician was referred by another physician, 36 percent stated that theix obstetrician was highly recommended by friends, and 14 percent stated that their obstetrician was recommended by close relatives. Nineteen percent chose their obstetricians on the basis of his reputation, and eleven percent had known their obstetrician previous to the present pregnancy. The final four percent knew their obstetricians through business and sociai acquaintarces.

Ninety percent of the entire sample contributed additional unsolicited comments about their present obstetricians. Fifiy-four percent stated that they were receiving excellent health care, eight percent perceived their obstetricians as dependable, and seven percent perceived them as competent in their field. Six percent described their obstetricians as compassionate, seven percent termed them as kind, and one per- 
cent acknowledged them as being friendly. Four percent of the subjects stated that they were totally confident in their obstetricians, and three percent volunteered that their obstetricians were capable of making them feel at ease.

Due to the nature of the topic under discussion, it seemed useful to assess the data in terms of whether or not a statistical relationship affording some predictability was apparent between the various independent variables and the dependent variables of attendance in natural childbirth classes and anxiety test scores. Therefore, a stepwise linear regression program (PSU: IBM-1130) was performed which determined the coefficients of a linear equation in the form: $Y=b_{0}+b_{1} x_{1}=b_{2} x_{2}+$ $\ldots+b_{n} x_{n}$ which best approximated the observations in the least-squares sense. The independent variables $(N=27)$ were entered into the equation on the basis of a variance criterion of one percent. At the first step of the sequence, a regression equation consisting of one independent variable which contributed most to the prediction of the dependent variable was developed. In succeeding steps of the sequence, additional variables were introduced which jointly provided the best prediction. Goodness of prediction was measured by the squared multiple correlation coefficients.

The first dependent variable assessed was attendance in natural childbirth classes. The independent variable which contributed most heavily to the prediction of class attendance was husband interest in attending labor and delivery. The coefficient of multiple correlation was computed to be .40 , which is statistically significant at the .001 level (d.f. 1, 70; $F=13.35$ ). The second independent variable which jointly provided the best prediction with the first independent variable 
was the number of children presently living at home. An analysis of variance testing the significance of the regression showed the equation to be significant at the .001 level (d.f. 2,$69 ; F=13.72$ ). The coefficient of multiple correlation was computed to be .53. The coefficient of partial correlation between the independent variable and the dependent variable when the effects of the variable of husband interest were eliminated was found to be -.38 , yielding a t-statistic of -3.46 , which is significant at the .001 level (d.f. 70).

The third independent variable introduced into the equation was trait anxiety test scores. The coefficient of multiple correlation was computed to be .59, which is significant at the .001 level (d.f. 3, 65; $F=12.11)$. The partial $\underline{x}$ was found to be -.30 , yielding a $\underline{t}$-statistic of -2.58 , which is significant at the .01 level. The fourth independent variable introduced into the equation was state anxiety test scores. The coefficient of multiple correlation was computed to be .65 , which is significant at the .001 level (d.f. 4, 67; F = 12.55). The partial $\underline{r}$ was found to be .35 , yielding a t-statistic of 3.07 , which is significant at the .001 level. The fifth independent variable. introduced into the equation was income level. The ccefficient of multiple correlation was computed to be .69 , which is significant at the .001 level (d.f. 5, 66; $F=11.8 \dot{5})$. The partial $\underline{x}$ was found to be .28 , yielding a $\underline{t}$-statistic of 2.38, which is significart at the .05 level.

The sixth independent variable introduced into the equation was interest in breastfeeding. The coefficient of multiple correlation was computed to be .72 , which is significant at the .001 level (d.f. 7, 64; $F=11.13)$. The partial $\underline{x}$ was found to be -.26 , yielding a $\underline{ \pm}$-statistic of -2.20 , which is significant at the .05 level. 
The preceeding seven independent variables have been reported individualiy, in order to illustrate their separate effects in predicting the dependent variable of attendance in natural childbirth classes. In the final. step of the linear regression sequence, a combination of 23 out of the 27 independent variables was found to be a significant predictor of class attendance. An analysis of variance significant at the .001 level (d.f. 23, 48; $F=4.02$ ), showed that regression is indeed useful for the prediction of this variable. The multiple correlation coefficient was computed to be .81 , which may be interpreted to mean that 66 percent of the total variance of the dependent variable is accounted for from the knowledge of the 23 independent variables. The four variables which did not contribute significantly to the regression equation at the .001 probability level were the following: weight gain, health problems associated with this pregnancy, perceived obstetrician support, and perceived obstetrician satisfaction with the subjects' progress.

The second dependent variable to be assessed by means of multiple regression was state anxiety test scores. The independent variable which contributed most heavily to the prediction of state scores was irait anxiety test scores. The multiple correlation coefficient was computed to be .70, which is statistically significant at the .001 level (d.f. 1, 70; $F=120 . \dot{8} 8)$. The second independent variable which jointly provided the best prediction of state scores with the first independent variable was the subject's perception of obstetrician satisfaction with their progress. The multiple correlation coefficient was computed to by .83, which is significant at the .001 level (d.f. 2,$69 ; F=74.05$ ). The coefficient of partial comrelation between state scores and perceived obstetrician satisfaction when the effects of the first independent variable 
were eliminated was found to be -.36 , yielding a t-statistic of -3.26 , which is significant at the .0I level (d.f. 70).

The third variable entered into the equation was general state of health. The multiple correlation coefficient was computed to be .84 , which is significant at the .001 level (d.f. 3, 68; $F=55.53$ ). The partial $\underline{r}$ was found to be -.30 , yielding a t-statistic of -2.56 , which is significant at the .02 level. The fourth variable entered into the equation was attendance at natural childbirth classes during a previcus pregnancy. The multiple correlation coefficient was computed to be .86 , which is significant at the .001 level (d.f. 4,67; $F=48.31$ ). The

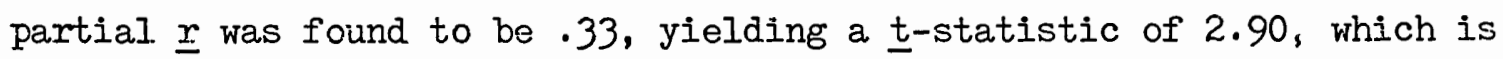
significant at the .01 level. The fifth variable entered into the equation was marital status. The multiple correlation coefficient was computed to be .87, which is significant at the .001 level (d.f. 5, 66; $F=42.93)$. The partial $\underline{x}$ was found to be -.29 , yielding a $\underline{t}$-statistic of -2.50 ; which is significant at the .02 level.

The sixth variable entered into the equation was interest in taking a course in baby care. The multiple correlation coefficient was computed to be .89 , which is significant at the .001 level (d.f. 6, 65; $F=40.64$ ). The partial $\underline{x}$ was found to be .32 , yielding a $\underline{t}$-statistic of 2.76, which is significant at the .01 level. The seventh variabie entered into the equation was general attitude towards the present pregnancy. The multiple correlation coefficient was computed to be .89 , which is significant at the 001 level (d.f. 7, 64; $F=36.6]$ ). The partial $\underline{r}$ was found to be -.26 , yielding a $t$-statistic of -2.15 , which is significant at the .05 leyel. The eighth variable entered into the equation was attendance at naturai childbirth classes during the present 
pregnancy, The mutiple correlation coefficient was computed to be .90 , which is significant at the .001 level (d.f. 8, 63; $F=34.43$ ). The partial $\underline{x}$ was found to be .26 , yielding a t-statistic of 2.15 , which is significant at the .05 level.

The preceeding eight independent variables have been reported individually, in order to illustrate their separate effects in predicting state anxiety test scores. In the final step of the linear regression sequence, a combination. of all the 27 independent variables was iound to be a significant predictor of state scores. An analysis of variance significant at the .001 level (d.f. 24, 44; $F=10.52)$, showed that regression is indeed useful for prediction of this variable. The multiple correlation coefficient was found to be .93 , which may be interpreted to mean that 87 percent of the total variance of the dependent variable is accounted for from knowledge of the 27 independent variables.

The third dependent variable assessed by means of multiple regression was trait anxiety test scores. The independent variable which contributed most heavily to the prediction of trait scores was state anxiety test scores. The multiple correlation coefficient was computed to be .80, which is significant at the .001 level (d.f. 1, 70; $F=120.88$ ). The second independent variable which jointly provided the best prediction of trait scores with the first independent variable was atiendance at natural childbirth classes during the present pregnancy. The multiple correlation coefficient was computed to be .83 , which is significant at the .001 level (d.f. 2, 69; $F=78.26$ ). The coefficient of partial correlation between trait scores and atterdance when the effects of the first independent variable were eliminated was found to be -.41, yielding a t-statistic of -3.70 , which is significant at the .001 level. The 
third variable entered into the equation was marital status. The multiple correlation coefficient was computed to be .85 , which is significant at the .001 level (d.f. 3,$68 ; F=58.72$ ). The partial $\underline{x}$ was found to be .30 , yielding a $\underline{t}$-statistic of 2.59 , which is signjificant at the .02 level.

The fourth variable entered into the equation was interest in taking a course in baby care. The multiple correlation coefficient was computed to be .86, which is significant at the .001 level (d.f. 4, 64; $F=47.13)$. The partial $\underline{r}$ was found to be -.24 , yielding a $\underline{t}$-statistic of -2.04 , which is significant at the .05 level. The fifth variable entered into the equation was the number of children presently living at home. The multiple correlation coefficient was computed to be .87 , which is significant at the .001 level (d.f. 5, 66; $F=40.79$ ). The partial $\underline{x}$ was found to be -.26, yieläing a t-statistic of -2.19 , which is significant at the .05 level. The sixth variable entered into the equation was interest in breastfeeding. The multiple correlation coefficient was computed to be .88, which is significant at the .001 level (d.f. 6, 65; $F=36.40$ ). The partial $\underline{r}$ was found to be .25 , yielding a $\underline{t}$-statistic of 2.07 , which is significant at the .05 level.

The six preceeding variables have been reported individually, in order to illustrate their separate effects in predicting the dependent variable of trait anxiety test scores. In the final step of the linear regression sequence, a combination of 24 out of the 27 independent variables was found to be a significant predictor of trait scores. An analysis of variance significant at the .001 level (d.f. 24,$47 ; F=9.76$ ), showed that regression is indeed usefui for prediction of this variable. The multiple correlation coefricient was computed to be .91 , which may be 
interpreted to mean that 83.percent of the total variance of the dependent variable is accounted for from knowledge of the 24 independent variables. The three variables which did not contribute significantly to the regression equation at the .001 probability level were the following: special health problems associatied with this pregnancy, subjects' mothers' description of what to expect in labor and delivery, and prime sources of information about childbirth.

At the time of the second testing administration, 29 subjects had attended natural childbirth classes and 42 suijjects had not. One subject delivered prematurely and was dropped from the study. Three subjects who were uncertain about classes at the start of the study decided to attend, and the remaining six subjects who were uncertain at the start of the study decided not to attend classes during the present pregnancy.

The number of months pregnant at the time of the second testing administration ranged from 7.8 to 9 , with the mean number of months being 8.5. Ninety-seven percent of the subjects in the subsample of women who had attended natural childbirth classes stated that things had been going well in general, and 98 percent of those women reported that they did not have any special problems associated with the present pregnancy. . All subjects in both groups reported that their obstetricians were satisfied with their progress. Only one subject out of the entire sample had taken a course in baby care prior to the second testing administration, a.lthough several subjects from both groups planned to ta.ke such a course at a later date.

One hundred percent of those women who had attended natural childbirth classes expressed a favorable reaction to the classes. All of those women whose hushands had attended classes with them reported that 
their husbands' reactions were quite favorable also. The subjects were asked to report how frequently they practiced the exercises that they had learned. Their responses ranged from once a day to once a week, with the mean number being four times per week. The subjects were divided approximately equally between attendance at PACE (Portland Association for Childbirth Education) and attendance at classes given through Fortland area hospitals.

State anxiety test scores in the subsample of subjects who had attended natural childbirth classes ranged from 20 to 49 , with a mean score of 31.83 and a standard deviation of 8.64 . State scores in the subsample of subjects who did not attend classes ranged from 20 to 71 , with a mean score of 39.74 and a standard deviation of 13.36 . The mean difference between groups was calculated to be 7.91. A Mann-Whitney UTest yielded a $\underline{z}$ velue of 2.51 ( $N=71)$, which is significant at the five percent level, showing that the chance of the medians of the two groups being the same is very small. Trait anxiety test scores in the subsample of subjects who had attended natural childbirth classes ranged from 21 to 51, with a mean score of 32.34 , and a standard deviation of 7.90 . Trait scores in the subsample of subjects who did not attend classes ranged from 20 to 67 , with a mean score of 39.24 , and a standard deviation of 10.75. The mean difference between groups was calculatea to be 6.90 . A Mann-Whitney U-Test yielded a $\underline{z}$ value of 2.70 ( $N=71$ ), which is significant at the one percent level, showing that the medians of the two groups are not equal.

Analyses were also performed to determine whether the changes in state and trait scores over the two month testing interval were signiricant. Changes in state scores ranged from -32 to +30 , with a mean change 
score of +3.97 , and a standard deviation of 10.90. A Mann-Whitney UTest yielded a $\underline{z}$ value of $2.79(\mathrm{~N}=71)$, which is significant at the one percent level, showing that the medians of the two groups are not equal. Changes in trait scores ranged from -15 to +22 , with a mean change score of 1.08 , and a standard deviation of 7.03. A Mann-Whitney U-Test yielded a $\underline{z}$ value of $.89(\mathrm{~N}=71)$, which is not significant at the five percent level.

Since a significant difference was found in changes in state scores over the two month testing interval, Wilcoxon Sign Tests were performed to determine which group had made a significant change in anxiety test scores. The mean state score of the subsample of subjects who had attended classes was found to have decreased .40 from the mean value of the first testing administration. The test yielded a signed-rank value of $207.00\left(\underline{n}^{\prime}=27.\right)$, which is not significant at the five percent level, using a two-tailed test. The mean state score in the subsample of subjects who did not attend na.tural childbirth classes was found to have increased 5.47 f'rom the mean value of the first testing administration. The test yielded a signed-rank value of $173.50\left(\underline{n}^{\prime}=39\right)$, which is significant at the one percent level, using a two-tailed test. The conclusion is made that state scores increased significantly over the two month testing interval in the group of subjects who did not attend classes, while state scores slightly decreased over the same interval in the group of subjects who did attend natural childbirth classes.

Wilcoxon Sign Tests were also performed, to determine whether or not there had been any significant changes in trait anxiety test scores. The mean trait score in the subsample of subjects who had attended classes was found to have decreased .78 from the mean value of the first testing 
administration. The test yielded a signed-rant value of 206.00 (ㅁ' $=$ 25), which is not significant at the five pexcent level, using a twotailed test. The mean trait score in the subsample of subjects who had not attended natural childbirth classes was found to have increased .48 from the mean value of the first testing administration. The test yielded a signed-rank value of $322.00\left(\underline{u}^{\prime}=40\right)$, which also is not significant at the five percent level, using a two-tailed test. The conclusion is made that trait anxiety test scores were not significantly changed in either group over the two month testing intervai. 


\section{DISCUSSION}

The purpose of the present study was to investigate the effect of natural childbirth training on anxiety in pregnant women. Maternal a.nxiety has been associated with a number of physiological and psychological problems, both for the mother and the developing infant. A review of the literature has demonstrated that objective evaluations of the training program are almost nonexistent. A few, specific variables have been investigated in limited nedical studies with general agreement about the results.

To date, only two empirical studies have addressed themselves to the relationship between psychological factors involved in pregnancy with respect to attendance in a natural childbirth program. Chertok (1959), in a study of painless chilabbirth, found higher anxiety levels. among the group of women who decided to attend natural childbirth classes as compared to the group who did not attend such classes. These results conflict with those of Tanzer (1967), who found no initial difference between groups on any one of a number of psychological and physiological variables, one of which was a measure of levels of anxiety. Both investigators used the TMAS and administered it to subjects at varying intervals before and after delivery.

Sunsequent to the conclusion of these studies, the STAI was developed to provide a comprehensive assessment of anxiety, including separate measures of state anxiety and trait anxiety. The STAI has been used in numerous studies since its development, and appears to provide a more sensitive measurement than other anxiety tests which preceeded it. In light of the contradictory results and somewhat confusing stud- 
jes of the relationship between anxiety and natural childbirth training, the STAI was used in the present investigation in an attempt to determine whether or not natural childbirth training was effective in reducing the anxiety commonly associated with pregnancy and delivery.

The most startling conclusion that emerges from this study was that an initial difference was found between groups on measures of trait anxiety. Those women who elected to attend natural childbixth classes evidenced a much lower level of trait anxiety than those women who elected not to attend. This finding is significant in view of the fact that an esseritial personality difference existed between groups Iron the start, although it is impossible to determine how much this one measure influenced the subjects' choice of whether or not they would attend.

According to Spielberger (1972), persons hith in A-Trait are more vunerable to stress and tend to experience A-State reactions of greater. intensity and with greater frequency than persons who are low in $A$-Prait. However, since trait anxiety refers to relatively stable individual. differences in anxiety proneness, A-Trait scores are not expected to change in response to situational stress. The present findings support Spielberger's (1970) conceptual distinction between state and trait anxiety. The initial difference in trait anxiety between groups as measured at a point approximately eight weeks before delivery remained a constant difference when measured again at a point apprcximately two weeks before the expected deIivery date, and there was no significant change in trait scores over time in eitlier group.

According to Spielberger's theory, whether ox not a person high in A-Trait will show an elevation in A-State depends upon the extent to which he perceives a specific situation as being threatening. Further- 
more, persons high in A-Trait would be expected to show greater elevations in A-State than persons Iow in A-Trait in situations involving some threat to self-esteem, but not in situations that involve physical danger unless personal adequacy is also threatened.

The assumption cannot be made that pregnancy and delivery are conceived of as being purely physical dangers. Numerous investigators have reported specific fears and concerns among pregnant women as a whole. These include fear of pain, bodily injury, and death, a.s well as concerm for the normalcy of the child and adequacy as the mother. Interestingly, Kagan and Moss (1962) found that the amount of fearfulness an adult has about injury to his body is significantly related to the amount of such fearfulness he experienced in early childhood.

In making the assumption that pregnancy and delivery involve both physical danfer and personal evaluation, one would hypothesize that the group of subjects characterized as a whole by high A-Trait scores and nonattendance at natiral childbirth ciasses, would experience greater elevations in A-State anxiety as the delivery date becane imminent, as opposed to the group of subjects characterized by low A-Trait scores and attendance at such classes. The results were consistent with this hypotresis.

Initially, there was no evidence that a significant difference existed between groups in state anxiety. After a two month interval, a dramatic increase in state scores was shown by the group of subjects who had chosen not to attend natural childbirth classes and who had evidenced high A-Trait scores. A closer examination of the results revealed that state scores actually decreased over time in the natural. childbixth grcup. The results of the present study do not support the 
findings of either of the two previous investigations of anyiety and its relationship to natural childbirth training.

In light of the studies of anxiety during pregnancy reported elsewhere in the literature (Ferreira, 1969; Joffee, 1969; Richardson \& Guttmacher, 1966), it would seem plausible to assume that regardless of trait anxiety level, all subjects should have experienced some elevation in state anxiety as the time for delivery drew near, with high A-Trait individuals experiencing A-State reactions of higher intensity than persons low in A-Trait.

There is general agreement in the literature that cognitive factors play a crucial role in the arousal of arixiety states, and that when aroused, a person becomes motivated to engage in various behavioral operations in order to minimize the discomfort associated with that state. The speculation is made that the group of women with lower levels of A-Trait were able to engage in a more adaptive form of coping behavior, in order to effectively reduce their anxiety by attending classes, than the group of women with higher levels of A-Trait who chose not to attend.

The existence of defense mechanisms is almost universally acknowledged. Levitt (1967) points out that one of, the most common methods for defending against anxiety is to avoiä the stimuli and circumstances that arouse it. Lazarus (1966) agrees with his essumption in that a person is likely to resoxt to defensive avoidances if he fails to get emotional relief from his search for an effective means of coping. It seems plausible to assume that one group of subjects, characterized by high trait anxiety leveis, engaged in defensive avoidance beharior by electing not to attend natural childbirth classes. 
A tentative explanation of this behavior could, perhaps, be interpreter in terms of the concept of stinulus generalization. Dollard and Miller (1950) suggested that one of the consequences of strong anxiety is . that the individual tends to respond anxiously to stimuli that are similar to an original anxiety-provoking stimulus. Perhaps the women in the non-attending group were less able in general to discriminate between positive aspects of their pregnancies and the associated negative aspects. Therefore, they would have been unwilling to participate in a program that would bring then into contact with more anxiety-provoking stimuli.

It also seems reasonable to assume that the group of women who undertools natural chilabisth training experienced a reduction of state anxiety as a direct result of participation in the program. A close examination of the nature of this training supports this hypothesis. It would appear as if participation in the program resulted in desensitization from repeated exposures to previously anxiety-producing stimuli.

Desensitization may have been acquired through one or several of the following essential elements of the natural childbirth training -program: 1) social reassurance 2) relaxation training 3) enotional adaptation 4) role playing 5) preparatory information. Both Jacobson (1938) and Wolpe (1965) lent support to the principle of reciprocal inhibition from their work with relaxation txaining and systematic desensitization, respectively. The essence of this principle is that if a response inhibitory of anxiety can be made to occur in the presence of anxiety-evoking stimuli, it will weaken the bond between these stimuli and the anxiety. This principle appears to be a basic consideration in the training program. 
The program rould also seem to be particularly effective in reducing anxiety by satisfying the need for social reassurance. Many studies have demonstrated that during times of anxiety and fear, most people have a strong need for affiliation. Schachter (1959) suggests two motives that might give rise to this increased need: 1) the need to evaluate one's own feelings by comparing them to others, and 2) the need to obtain reassurance from being in the presence of others who will be supportive because they are in a similar situation.

Seeking the presence of other pregnant women appears to be a very beneficial and adaptive form of coping behavior. The informal discussions provided at weekly meetings in the natural childbirth training program enable the participants to openly discuss their.apprehensiveness towards the situation, and ary misinformation about pregnancy and delivexy procedures is immediately corrected. Fears are dealt wi.th in a realistic manner, and participants are taught specific exercises and tachniques which are designed to reduce their chances of beconing overwhelmed by helplessness when labor actually bosins. Interestingly, previous research has demonstrated that scores on the A-State scaie decrease as a resilt of relaxation training (Spjelbexger, et al., 1970).

This leads to a further point which deserves recognition. Natural childbirth training can be considered extremely berieficial in terms of providing preparatory information. A series of studies by Janis (1969) sipport the general hypothesis that the intensity of fear evoked by a stressful event can be reduced by prior exposure to a preparatory communication that correctly preajicts the event.

Participants in a natura]. childbirth training program receive advance information about all aspects of labor and delivery. Their educa- 
tion often includes a film of a woman giving bixth, and they are encouraged to visit the hospital in order to farnilarize themselves with the new environment. One of the main implications of several studies reported by Janis (1958) was that a hospital patient is abie to cope with postoperative stress better if he is given realistic information beforehand on what is likely to happen.

The question then arises whether or not a relatively anxious person would respond dififerently to anxiety-provoking communication from someone whose level was normally low. In other words, would the group of women characterized by high A-Trait receive similar benefits from obtaining preparatory information about labor and delivery as the group of women characterized by low A-l'rait? A study done by Janis and Feshbach (1954) suggests that they would not. These investigators founa that the chronically most anxious showed diminished acceptance of arxiety-provoking communication.

It would appear then, that the average person is responsive to reassuring recommendations about how to cope with an anticipated danger when his level of anxiety is aroused to a moderate degree, rather than when it is aroused to a very nigh degree.

These findings suggest that preparatory coinunication should be tailored to fit the individual needs of the subject. Froponents of the natural childbirth program claim that education is effective in reducing the anxiety associated with preguancy and delivery. This type of communication may be successful with moderetely anxious women but would defeat its purpose by strengthening the defenses of those who are unable to confront and anticipate the more unpleasant aspects of childbirth. 
The need for further evaluative research in this area is readily apparent. To date, the number of naturalistic studies of anxiety is . small as methodological probiems in the natural setting are greatly magnified. Although no causal relationships have been demonsirated, the pathological nature of anxiety during pregnancy is quite clear, and attempts at its reduction should be given strong community support. In conclusion, future research should take into account the content of the natural childbirth training program, as it may differentially affect the way a woman copes with the anxieties of pregnancy and delivery, depending in part upon her basic personality traits. 


\section{REFTHRENCES}

Bean, A.C. Methods of childbirth. New York: Doubled.ay \& Co., 1972.

Buxton, C.I. A study of psychophysical methods for relief of childbirth pain. Philadelphia: W.B. Saunders Co., 1962.

Cattell, R.B. \& Scheier, I.H. Handbook for the IPAT Anxiety Scale. Illinois: Institute for Personility and Ability Testing, 1963.

Catte1.1, R.B. \& Scheier. I. Fi. The meanirg and measurement of nouroticism and anxiety. New Yurk: Ronald Press, 1961.

Chertox, I. Psychosomatic methods in painzess childbirth. New York: Pergamon Press, I959.

Copens, S.A. Wumen prenatal efrect:3. Merrill-Palmer Quarteriy, 1974, 20,43 .

Davids, A., \& DeVault, $\mathfrak{G}$. Matemal anxiety during pregnancy and childbirth abnormalities. Psychosonatic Medicine, 1962, 24, 454.

Davids, A., \& DeVault, :3. \& Talmadge, M. Arxiety, pregnancy, and childbirth abnornalities. Journai of Consulting Isychology, 196], 25, 74.

Davids, A., \& DeVaut, s.., đalnadge, in. Psychological study of emotional factors in pregnancy. Psychosomatic Medicine, 1961, 33, 93 (b).

Davids, A., Holde, R.A. B Gray, G.B. Matemal anxiety during pregnancy and adequacy of mother and child adjustment eight months foliowing childbirth. Chila Development, 1963, 34, 993.

Davis, O.D. \& Morrone, F.A. An objective evaluation of a prepareà childbirth program. American Journal of Obstetrics ana Gynecology, $1962,84,1196$.

Dick-Read, G. Childbirth without fear. New Ýon: Harper \& Brothers, 1953.

Dollard, J., \& Wiiler, N.E. Personality and psychotherapy. New York: NeGraw-Hill, 1950.

Doty, B.A. Relationships among attitudes in pregnancy and other matemal characteristics. Journal of Genetic Psychology, 1967, 1.1.1, 203.

Eâtrads, K.A. Psychological changes associated with pregnancy and obstetric complications. innublishea doctorel dissertation, University of Miami, 1969. 
Ferreira, A.J. Prenatal environment. Springfield, Illinois: Charles C. Thomas, 1969.

Grimm, E.R. Psychological tension in pregnancy. Psychosomatic Medicine, $1961,23,521$.

Jacobson, E. Progressive relaxation. (2nd ed.) Chicago: University of Chicago Press, 1938.

Janis, I.I. Psychological stress. New York: Wiley, 1958.

Jaris, I.I. Stress and frustration. New York: Harcourt Brace Jovanovich, Inc., 1969.

Janis, I.I. \& Feshbach, J. Personelity differences associated with responsiveness to fear-arousing communications. Journal of Personality. 1954, 23, 154.

Jenkins, T.T. \& Lykken, D.T. Individual differerces. Annual Review of Psychology, 19\%, 8, 70,

Joffee, J. Prenatal detexminants of behaviour. New York: Pergamon Fress, 1969.

- Kagan, J. \& Moss, H.A. Birth to maturjty. New York: Hiley, 1962.

Laird, M.D. \& Hogan, M. An elective program of preparation for childbirth. American Joumal of Obstetrics and Gynecology, 1956, ?2, $64 ?$.

Levitt," $\mathrm{E} . \mathrm{E}$. The psychology of enxiety. Indianapolis: Bobbs-Merrill, 1967.

Mandy, A.J.' Is natural childbirth natural? Psychosomatic Medicine, $1952,24,+31$.

Mcieynolds, P. The assessment of arxiety. Advances in psychological assessment, eaited by $P$. NoReynolds. Palo Alto: Science and Behavior Bcokss, 1968.

Richardson, S.A, \& Guttmacher, A.F. Childbearing: Its social and jsychological aspects. Balitimore: Williams \& Wilkins, 1967.

Roche Iaboratories, How to use the State-Trait Anxiety Inventory (STAI). New York: Foffman-IaRoche, 1974:

Sarason, I.G. Hmpirical findings and theoretical problems in the use of anxiety scales. Psychological Bulletin, 1960, 57. 403.

Schachter, S.S. The psychology of affiliation. Stanford, Calif: Stanford University Press, 1959. 
Spielberger, C.D. Anxiety: Current trends in theory and research. New York: Academic Press, 1972.

Spielberger, C.D. Personal communication, 30 Dec. 1974.

Spielberger, C.D., Gorsuch, R.I. \& Lushene, R.E. State-Trait Anxiety Inventory. Tallahassee: Florida State University, 1968.

Tanzer, D.R. The psychology of pregnancy and childbirth. Unpubiished doctoral dissertation, Brandeis University, 1967.

Taylor, J.A. A personality scale of manifest anxiet.y. Journal of $A B-$ normal and Social Psychology, 1953, 48, 285.

Thoms, K., \& Karlovsky, E.D. Two thousand deliveries under a training for childbirth program. American Joumal of Obstetrics and Gynecology, 1954, 68, 279.

Wilde, G.J. Trait description and measurement by personality questionnaires. Handbook of modern personality theory, edited by R.B. Catteil. Chicago: Aldine, 1972. (Cited by C.D. Spielkerger, Anxiety: Current trends in theory and research. New York: Academic Press, 1972).

Wolpe, J. The comparative clinical status of conditioning therapies and psychoanalysis. In J. Wolfe, A. Salter, \& I.J. Reyna, The conditioning, therapies. New Yoxk: Holt, Rinehart and Winston, 1965.

Wright, E. The new childbirth. New York: Hart Publishing Co, 1971.

Zuckerman, M. The development of an affect adjective check list for the measurement of anxiety. Jourmal of Consulting Psychology, 1960, $24 ; 457$. 
V XICNRAd Y 


\section{LETTER TO POTENTIAL PARTICIFANTS}

Would you like to be involved in a scientific study about the psychological aspects of pregnancy? You would be helping in an important research endeavor which might ultimately be of benefit to other women. Involvement is voluntary, and consists of filling out ore short questionnaire now, and another short questionnaire in two months. You need not answer any question that you feel is personal, and all information will be kept completely confidential. I will never know your name; however, if you are willing to help out, I will make sure that a copy of the research results is made available to you through your doctor's office. One final note: please do not ask your doctor or his staff for more information because this is an independent study. Thank you very much. 
FACE SHEHET NUMBER ONE

Please answer the following questions:

1. How old are you?

2. Are you presently married?

3. What is the highest grade you completed in school?

4. What is the approximate income level for your entire household for a year?

5. Is this a planned. pregnancy?

6. How many times have you been pregnant?

7. How many children do you have at home now?

8. How has your general state of health been in the last five years?

9. How have your menstrual periods been in the past?

10. How much weight have you gained with this pregnancy?

11. Are there any special health problems associated with this pregnancy?

12. What is your general attitude towards this pregnancy?

13. Has your mother told you what to expect in labor and delivery?

14. How did your mother describe her childbirth to you?

15. What has been your prime source of information about childbirth?

16. Have you ever taken a course in baby care?

17. Are you interested in taking a course in baby care? 
18. Do you plan to take a course in baby care with this pregnancy?

19. Approximately how many weeks pregnant are you now?

20. Is your obstetrician supportive?

21. Is your obstetrician satisfied with your progress?

22. Are you interested in breast-feeding?

23. Are you interested in seeing the baby born?

24. Is your husband interested in attending labor and delivery?

25. Have you ever attended a natural childbirth course?

26. Do you plan to attend a natural childbirth course with this pregnancy?

27. What is your reason for answering either "Yes" or "No" to the above question?

28. If you plan to attend a natural childbirth course, what motivated your interest?

29. If you plan to attend, what do you expect. to get out of the course?

30. Why did you select your particular obstetrician? 


\section{FACE SHEET NUMBER TWO}

Please answer the following questions:

1. Approximately how many weeks pregnant are you now?

2. How have things been going in general?

3. Do you have any special emotional or physical problems?

4. How much weight have you gained with this pregnancy?

5. Is your obstetrician satisfied with your progress?

6. Did you attend a course in baby care with this pregnancy?

7. If you did, what was the name of the course and where was it held?

8. Did you attend a natural childbirth course during this pregnancy?

9. If you did, what was the name of the course and where was it held?

10. If you did attend a natural childbirth course, what was your reaction to the program?

11. What was your husband's reaction to the natural childbirth program?

12. If you did attend a natural childbirth program, how often do you practice the exercises that you leamed?

13. Please feel free to comment on any aspect of pregnancy that you feel is important and should be included in this research study. Thank you. 
DIRECTIONS: A number of statements which people have used to describe themselves are given below. Read each statement and then blacken in the appropriate circle to the right of the statement to indicate how you feel right now, that is, at this moment. There are no right or wrong answers. Do not spend too much time on any one statement but give the answer which seems to describe your present feelings best.

1. I feel calm

(1) (2) (3) (4)

2. I feel secure

3. I am tense

4. I am regretful

5. I feel at ease

6. I feel upset

7. I am presently worrying over possible misfortunes

8. I feel rested

9. I feel anxious

10. I feel comfortable

11. I feel self-confident

12. I feel nervous

13. I am jittery

14. I feel "high strung"

15. I am relaxed

16. I feel content

17. I am worried

18. I feel over-excited and "rattled"

19. I feel joyful

20. I feel pleasant 


\section{SELF-EVALUȦTION QUESTIONNAIRÉ}

STAI FORM X-2

NAME

DATE

DIRECTIONS: A number of statements which people have used to describe themselves are given belowi. Read each statement and then blacken in the appropriate circle to the right of the statement to indicate how you generally feel. There are no right or wrong answers. Do not spend too much time on any one statement but give the answer which seems to describe how you generally feel.

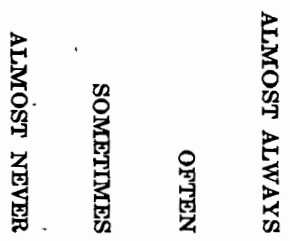

21. I feel pleasant

(1) (2) (3) (4)

22. I tire quickly

(1) (2) (3) (4)

23. I feel like crying

(1) (2) (3) (4)

24. I wish I could be as happy as others seem to be

(1) (2) (3)

25. I am losing out on things because I can't make up my mind soon enough ....

26. I feel rested

(1) (2) (3) (4)

27. I am "calm, cool, and collected".

(1) (2) (3) (4)

28. I feel that difficulties are piling up so that I cannot overcome them

29. I worry too much over something that really doesn't matter

(1) (2) (3) (4)

(1) (2) (3) (4)

30. I am happy

(1) (2) (3)

31. I am inclined to take things hard

(1) (2) (3)

32. I lack self-confidence

(1) (2) (3) (4)

33. I feel secure

(1) (2) (3) (4)

34. I try to avoid facing a crisis or difficulty

35. I feel blue

36. I am content

37. Some unimportant thought runs through my mind and bothers me .

38. I take disappointments so keenly that I can't put them out of my mind ....

(1) (2) (3) (4)

39. I am a steady person

(1) (2) (3)

40. I get in a state of tension or turmoil as I think over my recent concerns and interests 
APPENDIX B 
KEY TO CORRERAATION MATRIX

Number

Variable

Age

Marital Status

Educational Level

Income Level

Planned Pregnancy

Number of Previous Pregnancies

Number of Living Children

General State of Health

Menstirual History

Weight Gain

Special Health Problems

General Attitude

Mother as Source of Information

Mother's Description of Experiences

Prime Sources of Information

Prior Baby Care Course

Interest in Baby Care

Intend to Take Baby Care Course

Number of Weeks Pregnant

Perceived Obstetrician Support

Perceived Obstetrician Satisfaction

Interest in Breastfeeding

Seeing Baby Being Borm

Husband Interest

Prior Natural Childbirth Course

State Anxiety

Trait Anxiety

Attendance in Natural Childbirth Course 
TABLE I

CORRELATION MATRIX FOR VARIABLES

ONE THROUGH SEVEN

EXXPRESSED IN

HUNDREDTHS

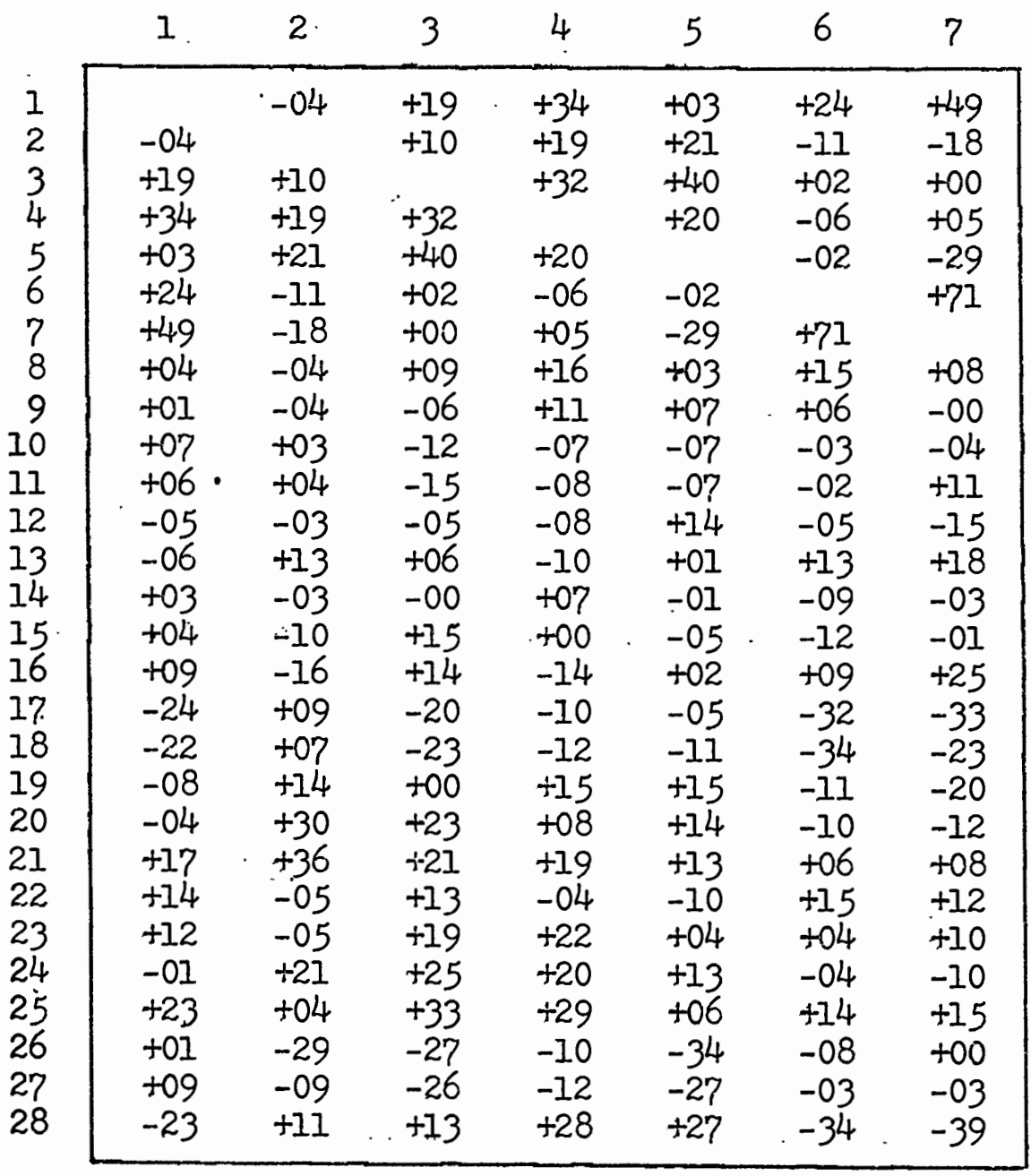


TABLE II

CORRELATION MATRIX FOR VARIABLES

EIGHT THROUGH FOURTEEN

EXPRESSED IN

HUNDREDTHS

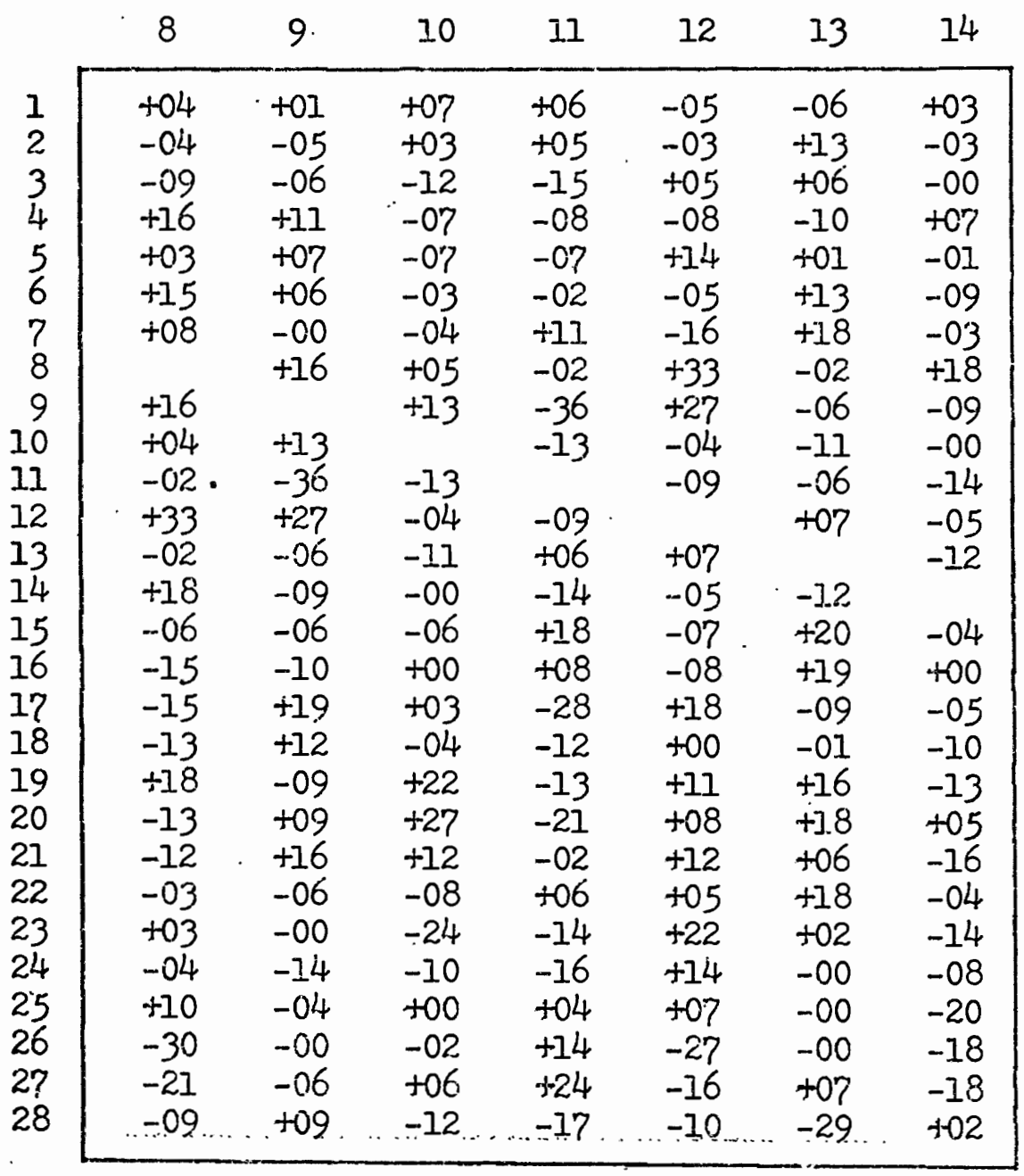


TABLE III

CORRELATION MATRIX FOR VARIABLES

FIFTEEN THROUGH TWENTY-ONE

EXPRESSED IN

HUNDREDTHS

\begin{tabular}{|c|c|c|c|c|c|c|c|}
\hline & .15 & 16 & 17 & 18 & 19 & 20 & 21 \\
\hline 1 & t04 & .09 & -24 & -22 & -08 & -05 & $+1 ?$ \\
\hline 2 & -10 & -16 & +09 & +07 & +14 & +30 & +36 \\
\hline 3 & +16 & +14 & -20 & -24 & +00 & +23 & +21 \\
\hline 4 & +00 & -14 & $\therefore-10$ & -12 & +15 & +08 & +19 \\
\hline 5 & -05 & +02 & -05 & -11 & +16 & +14 & +13 \\
\hline 6 & -12 & t09 & -32 & -34 & -11 & -10 & to6 \\
\hline 7 & -01 & +25 & -33 & -22 & -20 & -12 & +08 \\
\hline 8 & -06 & -15 & -15 & -14 & +18 & -13 & -11 \\
\hline 9 & -06 & -10 & +19 & +12 & -09 & +09 & +16 \\
\hline 10 & -06 & +00 & t03 & -04 & +22 & +27 & +12 \\
\hline 11 & +18. & +08 & -28 & -12 & -13 & -21 & -02 \\
\hline 12 & to7 & -08 & +18 & +00 & +11 & $\div 08$ & +12 \\
\hline 13 & +20 & +19 & -09 & -01 & +16 & +18 & +06 \\
\hline 14 & -04 & +00 & -05 & -10 & -13 & +05 & -16 \\
\hline 15 & & +04 & +04 & +05 & +01 & -09 & +00 \\
\hline 16 & +04 & & -23 & -15 & -03 & +21 & +14 \\
\hline 17 & +04 & -23 & & +66 & +12 & +12 & -06 \\
\hline 18 & +05 & -15 & +66 & & +02 & +05 & -13 \\
\hline 19 & t01 & -03 & +11 & +02 & & +18 & +22 \\
\hline 20 & -09 & +27 & +12 & +05 & +18 & & +41 \\
\hline 21 & +00 & +14 & -06 & -13 & +22 & $+4 I$ & \\
\hline 22 & +22 & +18 & -05 & -07 & $+0 ?$ & t08 & -03 \\
\hline 23 & -09 & -16 & +10 & +01 & +07 & -10 & +03 \\
\hline 24 & -08 & -13 & +25 & -10 & +37 & +23 & +13 \\
\hline 2.5 & -05 & -00 & -11 & -06 & +06 & +12 & +10 \\
\hline 25 & $\div 02$ & t06 & +10 & +16 & -18 & -10 & -29 \\
\hline 27 & \pm 00 & +12 & -04 & -04 & -18 & -06 & -09 \\
\hline 28 & +04 & -28 & +29 & +22 & +20 & +08 & -04 \\
\hline
\end{tabular}


TABLE IV

CORRETATION MATRIX FOR VARIABLES

TWENTY-TWO THROUGH TWENTY-EIGHT

EXXRESSED IN

HUNDREDTHS

\begin{tabular}{|c|c|c|c|c|c|c|c|}
\hline & 22. & 23 & 24 & 25 & 26 & 27 & 28 \\
\hline 1 & +14 & +12 & -01 & +23 & +02 & +09 & -24 \\
\hline 2 & -05 & -05 & +21 & +04 & -29 & -09 & +11 \\
\hline 3 & +13 & +19 & +25 & +33 & -28 & -26 & +13 \\
\hline 4 & -04 & +22 & +20 & +29 & -10 & -12 & +28 \\
\hline 5 & -10 & +04 & +13 & t06 & -34 & -27 & +27 \\
\hline 6 & +15 & +04 & -04 & +14 & -08 & -03 & -34 \\
\hline$?$ & +11 & +09 & -01 & +15 & +00 & -03 & -39 \\
\hline 8 & -03 & t03 & -04 & +10 & -30 & $-2 I$ & -09 \\
\hline 9 & -06 & -00 & -14 & -04 & -00 & -06 & t08 \\
\hline 10 & -08 & -24 & -10 & +00 & -02 & -06 & -12 \\
\hline 11 & t06 & -14 & -16 & +04 & +14 & +24 & -18 \\
\hline 12 & +05 & +22 & +14 & +07 & -28 & -17 & +10 \\
\hline 13 & +18 & 402 & -00 & -00 & +00 & $+0 ?$ & -29 \\
\hline 14 & -04 & -14 & -08 & -20 & -18 & -18 & $\div 02$ \\
\hline 15 & +22 & -09 & -08 & -05 & +03 & +00 & +04 \\
\hline 16 & +18 & -16 & -13 & -00 & +06 & +11 & -28 \\
\hline 1 & -05 & +10 & +25 & -11 & +10 & -04 & +29 \\
\hline 18 & -07 & tol & +10 & -06 & +15 & -04 & +22 \\
\hline 19 & to? & +07 & +37 & t06 & -18 & -18 & +20 \\
\hline 20 & +08 & -10 & +23 & +12 & -10 & -06 & t08 \\
\hline 21 & -03 & -03 & +13 & +10 & -29 & .09 & -04 \\
\hline 22 & & +00 & +06 & +00 & +00 & -08 & +12 \\
\hline 23 & +00 & & +41 & +13 & -19 & -21 & +24 \\
\hline & t06 & +41 & & +19 & -20 & -24 & +40 \\
\hline 2 & +00 & +13 & +19 & & +14 & +00 & tou \\
\hline & too & -19 & -20 & +14 & & +80 & -10 \\
\hline 27 & +08 & -21 & -24 & +00 & +80 & & -32 \\
\hline 28 & +12 & +23 & +40 & +04 & -10 & -32 & \\
\hline
\end{tabular}

